\title{
Interactive comment on "Biogeochemical processes accounting for the natural mercury variations in the Southern Ocean diatom ooze sediments" by S. Zaferani and H. Biester
}

\section{S. Zaferani and H. Biester \\ s.zaferani@tu-braunschweig.de}

Received and published: 30 April 2020

We would like to thank the reviewer for reviewing our manuscript and constructive comments/questions, which will improve the manuscript. Our responses to comments are shown below.

The paper present very important aspect of mercury fluxes in Antarctic region. There are very unique and valuable data. There are very interesting conclusions but firstly

1) (I) "to scavenge all water column Hg." - but this is not directly supported by the data. This is a rare situation that " $\mathrm{Hg}$ in the water column is removed through scavenging 
during diatom blooms" can you prove it? do you know situation that mercury concentration in that region was $0 \mathrm{pg} / \mathrm{L}$ ? do you know literature about this phenomenon? This is opposite to PCA results where mercury don't correlate with $\mathrm{Cp} 2$ appears to reflect phytoplankton blooms and export of biological materials or with $\mathrm{Cp} 1$ - load of lithogenic elements.

We used the Hg scavenging hypothesis, which has now been discussed for more than 10 years, as a basis for the $\mathrm{Hg}$ accumulation rates found in Adélie Basin sediments. Adélie Basin is for sure a situation which cannot be extrapolated to all productive area in the world's ocean. It is here not the question if the scavenging hypothesis is directly supported by our data, it is based on our data the only process which could explain such high $\mathrm{Hg}$ accumulation rates. We think that direct proof of this process can only be obtained by sediment trap analysis (we actually found this in lakes). The idea that mercury concentrations become $0 \mathrm{pg} / \mathrm{L}$ is too simplified. Scavenging is a continuous process and our model simply provides an explanation of how a $\mathrm{Hg}$ mass balance could be obtained (in lakes the strong decrease in $\mathrm{Hg}$ concentration can be observed). The Hg pool in the water column is not static but continuously "refilled" by mixing with water from areas that are not affected by algae blooms (blooms are a local/regional effect). In the real world, scavenging is a continuous process and most intense during and shortly after algae blooms. Scavenging does not only affect $\mathrm{Hg}$ but also other elements. For instance, accumulation rates of $\mathrm{Pb}$ in our sediments are about 166 times higher than in other pelagic sediments. However, we made this point now clearer in the manuscript. We cited several papers on this topic in the introduction of the manuscript and in particular we like to recommend the paper of Soerensen et al., 2014 which gives a good overview of $\mathrm{Hg}$ evasion from the ocean and $\mathrm{Hg}$ scavenging at the surface layer.

There is a simple reason why $\mathrm{Hg}$ does not correlate with biogenic silica (Cp2) in our PCA and this is not opposed to our hypothesis. Biogenic silica appears and varies in the percent range and $\mathrm{Hg}$ concentration range in the lower ppb range (and is the limiting factor based on the amount of $\mathrm{Hg}$ in the water column). So it cannot be expected that

Interactive

comment

OSD
Printer-friendly version

Discussion paper

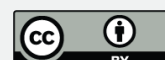


there is a correlation between biogenic silica and $\mathrm{Hg}$. Moreover, that $\mathrm{Hg}$ does not correlate with lithogenic elements is important information indicates that the $\mathrm{Hg}$ source is not lithogenic but atmospheric.

2) Cp4 including $\mathrm{Hg}$ described $1.35 \%$ of the variance which is marginally. Did you try to make PCA for three factors? I supposed it could be more useful.

Interactive

We do not understand the meaning of this suggestion. The percentage of variance covered by $\mathrm{Hg}$ is of no evidence here (it cannot be expected that $\mathrm{Hg}$ concentrations control the amount of biogenic silica). Why should a PCA with three factors be more "useful" here?

3) (II) Otherwise there are lack of comment whether these $\mathrm{Hg}$ values are high, toxic or not? why you didn't account a Vulcanic sources in this region? Describe $\mathrm{Hg}$ sources to the water in this region.

Explanation about how toxic are these concentrations is outside the scope of our study and would be rather speculative. The concentrations we found (especially in the upper core) are about 2-fold elevated compared to the (variable) natural background in the Adélie Basin, but we will not speculate how this affects the Antarctic marine food chain. Our PCA does not give any indication, that there is a significant volcanic $\mathrm{Hg}$ source in this area. Volcanic eruptions are usually short-term events and would appear as peaks in Hg records (see e.g. Pérez-Rodríguez et al., GCA 2019). The Hg record we found is characterized by periodic-like changes in concentrations that cannot be explained by a volcanic source.

4) (III) Why $\mathrm{Hg}$ and As correlated (Cp4)? Maybe this is explanation of $\mathrm{Hg}$ sources to the sediment?

Up to now, we do not understand this relatively weak correlation. We probably see similar scavenging processes here. What does the reviewer suggest regarding the same source of $\mathrm{Hg}$ and As in the sediments? 
And some specific comments:

5) - In the abstract (shortly, at least one sentence) and in the introduction section is lack of information why mercury is so important, why do you research $\mathrm{Hg}$ ?

We had mentioned in the introduction that $\mathrm{Hg}$ studies are of concern due to its toxic effects: "Mercury $(\mathrm{Hg})$ is a metal of environmental concern due to its ability to be transported from source to background regions (predominantly in the atmosphere) and be transformed into highly bioaccumulative and toxic methylated forms." However, we will add a sentence to the abstract: This has been added: "Due to its toxic nature and its high potential of biomagnification mercury is a pollutant of concern."

6) - I suggest more detail map of sampling station (Fig. 1)

Thanks for the suggestion but we think the map clearly shows the location of the core in Antarctica.

7) - Describe more detailed preparing the core to analysis: how do you determine the age of the sediment (sediment layers)? The 0-3.2 mbsf is the mixing layer?

The information regarding sample preparation before analysis is given in the Materials and Methods section. "All samples were freeze-dried and ground using a glass pestle prior to geochemical analysis." We added a reference to where we got the age model: Yamane et al. (2014). The 0-3.2 mbsf (meters below seafloor) is not water depth therefore it is not a mixing layer. This indicates depth in the sediment core. The core was taken during an IODP ship cruise, extensive data is available in the related reports and some published papers.

8) - How do you determine accumulation rates.

The accumulation rates were calculated from concentration (ng g-1) and dry mass sediment accumulation rate (bulk density of a sediment layer $(\mathrm{g} \mathrm{cm}-3)$ and the interval represented by the section $(\mathrm{cm})$, divided by the time duration $(\mathrm{yr}))$.

\section{OSD}

Interactive

comment
Printer-friendly version

Discussion paper 
9) - Too long title of 3.1 section.

The title has been modified to: Geochemical processes controlling the distribution of OSD the elements in sediments.

10) Line 148 "which includes positive loadings of lithogenic elements," - write which one.

These elements have been mentioned in the previous paragraph: "The first component (Cp1), explains $33 \%$ of the variance and shows large (>0.7) positive loadings of $\mathrm{Mn}$, $\mathrm{Ti}, \mathrm{Rb}, \mathrm{Zr}, \mathrm{K}$, and $\mathrm{Y}$ and moderate positive loading of Fe."

11) - figure 9 is missing in the text.

We referred to the figure in the manuscript.

Interactive comment on Ocean Sci. Discuss., https://doi.org/10.5194/os-2019-132, 2020. 